\title{
Hypophysitis, CTCAE
}

National Cancer Institute

\section{Source}

National Cancer Institute. Hypophysitis, CT CAE. NCI Thesaurus. Code C143193.

A disorder characterized by inflammation and cellular infiltration of the pituitary gland. 